\title{
Os caixeiros viajantes como agentes formadores de redes sociais no Rio Grande do Sul
}

The traveling clerks as agents for social networking in Rio Grande do Sul

\section{Caroline von Mühlen}

Pontifícia Universidade Católica do Rio Grande do Sul - PUCRS - Porto Alegre - Rio Grande do Sul - Brasil

\section{Rodrigo Luis dos Santos}

Instituto Superior de Educação Ivoti - ISEI - Ivoti - Rio Grande do Sul - Brasil

\begin{abstract}
$\longrightarrow$
Resumo: Este trabalho tem por objetivo apresentar alguns apontamentos acerca do projeto de pesquisa intitulado "Homens de negócios e de relações: os caixeiros viajantes como agentes formadores de redes sociais no Rio Grande do Sul (segunda metade do século XIX e primeira metade do século XX)". Este projeto encontra-se em fase de desenvolvimento e visa empreender uma análise da formação de redes sociais, econômicas e políticas estabelecidas pelos caixeiros viajantes no Rio Grande do Sul, contemplando o recorte temporal que inicia na segunda metade do século XIX até a primeira metade do século $X X$, período em que essa profissão passa a sofrer um declínio. Percebemos que estes agentes sociais são analisados de forma ainda muito precária pela historiografia, sobretudo no Rio Grande do Sul. Tendo em vista que os caixeiros viajantes desempenharam um papel de considerável importância econômica e, em decorrência disso, também se ocuparam de estabelecerem vínculos diversos e formas de sociabilidade, almejamos dar maior visibilidade para estes agentes históricos e, concomitantemente, visibilizar as estratégias utilizadas por eles, a partir de uma apreciação crítica de suas trajetórias pessoais, embasados em robusto embasamento teórico e metodológico, coerente com os avanços recentes da historiografia na área das relações sociais.
\end{abstract}

Palavras-chave: Caixeiros viajantes. Redes sociais. Rio Grande do Sul.

\begin{abstract}
This paper aims to present some notes about the research project entitled "Business men and relations traveling clerks as agents for social networking in Rio Grande do Sul (second half of the nineteenth century and first half of the twentieth century)". This project is in the development phase and aims to undertake an analysis of the formation of social, economic and political networks established by the traveling clerks in Rio Grande do Sul, contemplating the temporal cut that begins in the second half of the nineteenth century until the first half of the twentieth century, a period in which this profession begins to suffer a decline. We perceive that these social agents are analyzed in a very precarious way by historiography, especially in Rio Grande do Sul. Given that the traveling clerks played a role of considerable economic importance and, as a result, they also worked to establish diverse and forms of sociability, we aim to give greater visibility to these historical agents and, at the same time, to visualize the strategies used by them, based on a critical appraisal of their personal trajectories, based on a robust theoretical and methodological foundation, consistent with the recent advances in historiography in area of social relations.
\end{abstract}

Keywords: Travelers clerks. Social networks. Rio Grande do Sul. 


\section{Introdução}

Os caixeiros eram peças extremamente importantes na engrenagem de funcionamento das lojas e dos negócios. Realizavam os pagamentos e cobranças, cuidando ainda de toda a escrituração dos negócios dos patrões. $O$ fato de conhecerem os mecanismos de escrituração mercantil tornou-os indispensáveis aos comerciantes da Corte (MARTINHO, 1993, p. 38).

O presente artigo objetiva elencar alguns apontamentos acerca do projeto de pesquisa intitulado "Homens de negócios e de relações: os caixeiros viajantes como agentes formadores de redes sociais no Rio Grande do Sul (segunda metade do século XIX e primeira metade do século XX)". Reiteramos que este projeto encontra-se em fase de desenvolvimento e visa empreender uma análise da formação de redes sociais, econômicas e políticas estabelecidas pelos caixeiros viajantes no Rio Grande do Sul. Desse modo, contemplamos o recorte temporal que inicia na segunda metade do século XIX até a primeira metade do século $X X$, período em que essa profissão passa a sofrer um declínio.

Como bem demonstra a epígrafe que inicia essa introdução, os caixeiros viajantes desempenhavam um papel de extrema importância no mundo colonial, uma vez que eram os personagens encarregados de percorrer a região colonial e oferecer as novidades que eram oferecidas nas casas comerciais. Ou seja, ele se tornou o principal intermediário entre o comércio atacadista de Porto Alegre, passando pelos entrepostos maiores, geralmente localizados juntamente aos terminais fluviais, e terminando nas vendas menores localizadas no interior da colônia.

Dada a sua importância, percebemos que estes agentes sociais são analisados de forma ainda muito precária pela historiografia, sobretudo no Rio Grande do Sul. Tendo em vista que os caixeiros viajantes desempenharam um papel de considerável importância econômica e, em decorrência disso, também se ocuparam de estabelecerem vínculos diversos e formas de sociabilidade, almejamos dar maior visibilidade para estes agentes históricos e, concomitantemente, visibilizar as estratégias utilizadas por eles, a partir de uma apreciação crítica de suas trajetórias pessoais, embasados em robusto embasamento teórico e metodológico, coerente com os avanços recentes da historiografia na área das relações sociais.

Nas linhas que seguem, a discussão é iniciada com a trajetória de alguns caixeiros viajantes, seguindo com uma reflexão acerca de quem era o caixeiro viajante, com o intuito de situar o leitor quanto à sua importância e função. Em seguida é apresentado um breve resgate das atividades desse personagem, assim como, os locais e trajetos comumente percorridos, encerrando com as considerações para o meio social, cultural e econômico sul-rio-grandense.

\section{João Emílio Bender, Pedro Adams Filho e A.J. Renner: de caixeiros à homens de influência}

Quando falamos sobre os caixeiros viajantes, na maioria das vezes, a imagem que nos vem na lembrança está relacionada com aqueles homens que andavam de cidade em cidade, ou lugarejo em lugarejo, montados a cavalo e carregando bolsas e malas cheias de apetrechos e objetos para serem vendidos. Esta imagem, embora um pouco folclórica, também condiz com a prática de atuação destes agentes sociais. Hilda Flores descreve com mais detalhes a figura dos caixeiros:

o caixeiro viajante vestia bota de cano alto, conhecida por MusterreiterStüfel, provida de grandes esporas, bombacha, mais apropriada para semanas de cavalgadas, camisa xadrez, lenço ao pescoço e chapéu de aba larga para proteção contra a canícula, além do poncho ou capa de chuva - que A. J. Renner logrou impermeabilizar na década de 1880, especialmente para o caixeiro viajante, que também ele foi. Completava a indumentária o relho de cabo curto na mão direita e guaiaca na cintura, onde guardava o dinheiro e também a pistola (FLORES, 2000, p. 180).

Contudo, a ação e os caminhos percorridos pelos caixeiros viajantes vai muito além desta representação. Para demonstrar isso de forma mais clara, traremos a trajetória de três caixeiros que 
atuaram no Rio Grande do Sul entre o final do século $X I X$ e a metade do século $X X$.

O primeiro deles, menos conhecido, é João Emílio Bender. Nascido em 1885 no atual município de Novo Hamburgo - na época 2ำ Distrito de São Leopoldo -, começou a trabalhar como caixeiro viajante ainda muito jovem. Quando pensamos na figura do caixeiro, muitas vezes o enquadramos socialmente em um padrão de origem mais humilde, vindos de famílias pobres. Contudo, as pesquisas mostram que essa não era a regra. João Bender era membro de uma família que contava, desde a segunda metade do século XIX, de renome e influência política e econômica no distrito de Novo Hamburgo e em São Leopoldo. Seu pai era Luiz Bender (1845-1934), também natural de Novo Hamburgo.

Luiz Bender, assim como o filho, também ingressou muito jovem, aos quatorze anos de idade, na vida de caixeiro viajante. Além disso, fazia o transporte de produtos das áreas coloniais até o porto do rio dos Sinos, localizado em São Leopoldo. A profissão de caixeiro the valeu a formação de um pequeno capital, que possibilitou integrar, em 1963, a sociedade de uma companhia de transporte fluvial, que fazia o trajeto entre São Leopoldo e Porto Alegre. Passou a residir na sede municipal, aí constituindo um importante capital social, que o transformou em uma figura influente também na política local. Em 1885, recebeu do imperador D. Pedro II a patente de major da Guarda Nacional, sendo nomeado comandante do Primeira Seção de Infantaria da Guarda Nacional em São Leopoldo. Voltando a residir em Novo Hamburgo, abriu um comércio na localidade. Nesta mesma época, ingressou no Partido Republicano Rio-grandense (PRR). Tornou-se homem de confiança de Júlio de Castilhos, líder unipessoal do partido e presidente do Rio Grande do Sul entre 1893 e 1898, assim como de seu sucessor, Borges de Medeiros, que governou entre 1898 e 1908 e de 1913 a 1928. Elegeu-se conselheiro municipal em 1896, reelegendo-se consecutivamente até 1916. Foi durante 16 anos, entre 1900 e 1916, presidente do Conselho Municipal de São Leopoldo. Seu genro,
Guilherme Gaelzer Neto, casado com sua filha Emma, foi intendente de São Leopoldo entre 1902 e 1916.

Como visto, João Emílio Bender advinha de uma família abastada e de reconhecida influência na sociedade leopoldense. Sua atuação como caixeiro viajante estava ligada diretamente ao comércio familiar, atuando na revenda de produtos e na negociação comercial em diferentes localidades do Rio Grande do Sul. Tratava-se de, ao mesmo tempo, estabelecer a sua consolidação pessoal, através de sua prática relacional, e de ampliar o leque econômico e social já conquistado por sua família.

Bender casou-se com Wilma Teresa Bernd, que vinha de uma família tradicional do comércio em Novo Hamburgo. Seu avô paterno, Wilhelm Bernd, fundou uma casa comercial, que passou, posteriormente a ser administrada por seu pai, Felipe Bernd. Sobre a questão do matrimônio entre João Bender e Wilma Bernd, há um fato que demonstra que apenas o capital oriundo das relações sociais e econômicas não eram suficientes para facilitar os enlaces. Havia outros aspectos que poderiam beneficiar ou dificultar as uniões familiares. E um desses elementos era a religião dos envolvidos. As diferenças e divergências religiosas eram uma característica marcante das comunidades de origem imigrante, especialmente a alemã, nos séculos XIX e grande parte do XX. A família Bernd era católica. A mãe de Wilma, Guilhermina Gertrudes Wolffenbüttel Bernd era uma católica fervorosa, com liderança na comunidade local. Por outro lado, a família Bender era evangélico-luterana e envolvida com a Maçonaria. Por conta disso, Guilhermina foi contra o casamento, proibindo qualquer relação entre a filha e João Bender. Contudo, a jovem engravidou e, como costume da época, foram obrigados a casar. Guilhermina renegou a filha e, em seu leito de morte, anos mais tarde, não contou com a presença de Wilma.

Após alguns anos exercendo a profissão de caixeiro viajante, João Bender passou a atuar como tesoureiro da Intendência Municipal de São Leopoldo, durante parte do governo de seu cunhado, Guilherme 
Gaelzer Netto. As redes familiares e políticas Ihe renderam bons dividendos. Bender exerceu o cargo até 1916, quando Gaelzer Neto renunciou ao posto de intendente, por conta das querelas políticas locais, imbricadas com as disputas entre católicos e evangélico-luteranos.

O próximo caixeiro viajante cuja trajetória analisaremos é mais conhecido, sendo homenageado com uma das principais ruas da cidade de Novo Hamburgo. Trata-se do líder empresarial, político e confessional Pedro Adams Filho.

Pedro Adams Filho nasceu em 13 de abril de 1870, na localidade de Santa Clara do Sul, então distrito de Lajeado, falecendo em 9 de setembro de 1935, em Porto Alegre. Antes de radicar-se em Novo Hamburgo, residiu e trabalhou em Dois Irmãos então distrito de São Leopoldo - e Taquara. Com a experiência adquirida como fabricante de selas e no setor de curtumes, logo montou em Dois Irmãos uma pequena empresa, onde chegou a ter doze funcionários. Nessa fase, que durou em torno de sete anos, entre 1891 e 1898, Pedro Adams Filho passou a atuar também como caixeiro viajante, circulando por diferentes localidades do Rio Grande do Sul, vendendo os produtos que fabricava, entre eles selas, tamancos, sapatos e sandálias.

Em 1898, juntamente com a esposa e filha, muda-se para Novo Hamburgo, que já começava a despontar economicamente, por conta do setor coureiro-calçadista, dos matadouros instalados nesse distrito - Provenzano e Kroeff - e da linha da viação férrea, ligando Porto Alegre ao então distrito leopoldense. Em Novo Hamburgo, no ano de 1901, em sociedade com Frederico Gerhardt, funda a Fábrica de Calçados Rio-Grandense. Além do sócio, Frederico Gerhard, Pedro Adams Filho conta com o apoio, na gerência da empresa, de seu irmão, Alberto Adams. Com a saída de Frederico Gerhardt da sociedade, a empresa passa a denominar-se Pedro Adams Filho \& Cia. Ltda. No ano de 1917, investe no setor de curtumes, com a abertura do Curtume Hamburguez. Além do trabalho empresarial, também exerceu o cargo de agente do Banco da Província, o que contribuiu para a obtenção de créditos para o fomento de seus empreendimentos (e veremos que esta experiência bancária será importante em outras atividades ao final da década de 1920). Na vida social, Pedro Adams Filho foi, em 1911, um dos colaboradores na fundação do Esporte Clube Novo Hamburgo, clube de futebol existente até os dias de hoje, além de ter exercido, entre 1910 e 1911, o cargo de presidente da Sociedade Ginástica de Novo Hamburgo.

Sobre o tocante familiar, Pedro Adams Filho casou-se em 1891 com Rosalina Saenger, conhecida como Rosa, natural de Bom Jardim - atual município de Ivoti, na época distrito de São Leopoldo. O casamento ocorrera em Dois Irmãos. Rosalina, faleceu em 1924. Dois anos mais tarde, em 1926, Pedro Adams Filho se casaria pela segunda vez. Sua segunda esposa seria Olga Maria Kroeff, filha de Jacob Kroeff Filho e irmã de Jacob Kroeff Neto. Kroeff Neto era correligionário de Pedro Adams Filho no PRR, além de exercerem juntos a liderança da comunidade católica de Novo Hamburgo durante muito tempo, ao lado de Leopoldo Petry - primeiro intendente eleito de Novo Hamburgo, entre 1927 e 1930 - e José João Martins. Esse mesmo grupo, se destacou na liderança do movimento emancipacionista de Novo Hamburgo, iniciado em 1924, logo após os festejos do centenário da imigração alemã no Rio Grande do Sul, comemorações das quais Pedro Adams Filho foi um dos organizadores.

A trajetória de Adams Filho evidencia a capacidade de articulação e desenvolvimento de redes sociais alicerçadas nos mais diferentes campos, contemplando áreas como religião, política e sociabilidade. Nesse sentido, esses elementos também podem ser encontrados na trajetória de nosso terceiro agente histórica estudado, e com certeza, o mais conhecido dentre os três que escolhemos: Antônio Jacob Renner, mais conhecido nacionalmente como A. J. Renner.

Nascido em Alto Feliz - na época, localidade pertencente ao município de São Sebastião do Caí em 1884, A. J. Renner era filho de Jacob Renner natural de Bom Jardim, atual município de Ivoti - e 
Clara Fetter, residente em Alto Feliz. Ainda criança, mudou-se com sua família para cidade de Montenegro onde seu pai, em 1894, montou uma pequena refinaria de banha. Essa refinaria, anos mais tarde, seria dirigida pelo irmão de A.J., Júlio Renner, se tornando um dos maiores empreendimentos do Rio Grande do Sul, o Frigorífico Renner, desativado, após falência, em 1984. Foi na refinaria de banha de Jacob Renner que A.J. começou a trabalhar, aos doze anos de idade. Dois anos mais tarde, em 1898, mudou-se para Porto Alegre, onde aprendeu a profissão de ourives.

Em 1903, instalou-se em São Sebastião do Caí, importante polo comercial da região, abrindo uma ourivesaria. Casou-se, nesta mesma época, com Mathilde Trein, filha de uma tradicional família da cidade, cujo patriarca, Francisco Trein, passou a residir alguns anos antes, abrindo uma importante casa comercial. Com o passar dos anos, o comércio dos Trein se tornou o mais poderoso da região, sendo, naquele momento, dirigido pelo filho de Francisco, Christiano Jacob Trein, pai de Mathilde. A irmã de Mathilde, Catharina, casou-se com Frederico Mentz, nascido em Hamburgo Velho - localidade de São Leopoldo -, que também veio a ser um dos empresários mais importantes do Rio Grande do Sul entre as décadas de 1910 e 1930.

Tomando parte na empresa familiar de sua esposa, deixou o ofício de ourives e passou a exercer o cargo de caixeiro viajante da Christiano J. Trein \& Cia. Era responsável pela venda dos produtos e por estabelecer contatos comerciais em diferentes cidades do estado. Ocupou esse posto até 1911. Nesse mesmo ano, ingressou como sócio minoritário em uma tecelagem fundada pelo seu sogro e pelo cunhado Frederico Mentz, da qual era acionista majoritário Frederico Arnoldo Engel, outro importante comerciante de São Sebastião do Caí, que também atuou na política local, como conselheiro municipal. Além disso, Engel esteve envolvido com a fundação do Sínodo Rio-grandense, em 1886, entidade que passou a congregar as comunidades evangélicoluteranas do Rio Grande do Sul - e que em 1968 se transformaria na Igreja Evangélica de Confissão Luterano no Brasil, a IECLB.

Por sugestão de A.J. Renner, a tecelagem iniciou a fabricação de capas de chuva impermeáveis, inspiradas nos ponchos, vestimenta característica da região da Campanha. No ano seguinte, a direção da empresa e as maior parte das ações passaram para A.J., e a tecelagem adotou nova denominação: A.J. Renner \& Cia. Em 1917 a empresa deixa São Sebastião do Caí, transferindo-se para Porto Alegre, onde hoje está o atual bairro Navegantes. Investindo no setor de tecelagem e fiação, passou, na década de 1920, também a produzir trajes masculinos, que passaram a ser comercializados em larga escala, dando origem as Lojas Renner. Logo, outros ramos comerciais e industriais foram sendo explorados, como a produção de tintas e equipamentos, dando origem a um dos principais conglomerados empresariais do Brasil.

Além disso, A.J. Renner também atuou no campo da sociabilidade, apoiando a fundação do Grêmio Esportivo Renner - fundado em 1931, foi campeão estadual de futebol em 1954 - do Rotary Club de Porto Alegre, Club Leopoldina Juvenil e do Porto Alegre Country Club. Também financiou o Correspondente Renner, informe de notícias transmitido pela Rádio Guaíba, inspirado no Repórter Esso, transmitido pelas rádios Nacional, Globo, Tupi e Record. Foi ainda presidente do Centro das Indústrias do Rio Grande do Sul, atual Federação das Indústrias do Estado do Rio Grande do Sul - FIERGS. Na vida política, foi deputado classista, eleito de forma indireta, para a Assembleia Legislativa sul-riograndense, exercendo seu mandato entre 1935 e 1937, quando renunciou em decorrência de conflitos internos no legislativo estadual.

A.J. Renner, que tornou-se um dos empresários mais conhecidos do Brasil, faleceu em Porto Alegre, em 27 de dezembro de 1966, aos 82 anos de idade.

$\mathrm{Na}$ trajetória dos três agentes que elegemos como objetos de análise, a atuação como caixeiro viajante representou um momento significativo para estruturar a dimensão dos vínculos diversos com 
diferentes pessoas e grupos. A partir de João Emílio Bender, Pedro Adams Filho e A.J. Renner, é possível vislumbrar um panorama de possibilidades que puderam, ao menos, ser buscadas por outros caixeiros viajantes. Mas, fica uma questão: qual a razão de se pesquisar este grupo profissional? As respostas são encontradas ao analisarmos 0 panorama histórico onde estes agentes atuaram e suas contribuições para a economia e para a difusão de informações no meio social, político e cultural sulrio-grandense. E são estes aspectos que iremos explorar na sequência deste artigo.

\section{Um breve resgate das atividades de um caixeiro viajante ou Musterrreiter}

O trabalho árduo e diário, uma vida simples e de economias podem ser recompensados com a ascensão econômica e social. [...] $A$ conduta do comerciante passava a ser um exemplo a ser seguido. Ao adotar as normas de conduta do comerciante, o caixeiro esperava estar se preparando para um futuro muito próximo como proprietário (MARTINHO, 1993, p. 60).

Desde a chegada dos primeiros imigrantes alemães em 1824 até a elevação da Capela Curada de São Leopoldo à condição de Vila em 1846, foi descrito por Marcos Justo Tramontini como um período de improviso administrativo. Esse período foi marcado por constantes reivindicações dos colonos, pleitos judiciais envolvendo colonos alemães e nacionais, em decorrência da demora para a concessão dos lotes de terra, das medições confusas das propriedades e das dificuldades dos governantes com o fornecimento dos subsídios aos colonos, constituindo um emaranhado de confusões, disputas e mal-entendidos. Todavia, além dos problemas antigos vivenciados pelos habitantes de São Leopoldo (a chegada de novos imigrantes alemães, dificuldade em conceder os subsídios, problemas com a medição e regulamentação da terra), outros, como a valorização e especulação da terra, as mudanças desencadeadas pela aprovação da Lei de Terras de 1850 e a chegada de novos colonos, foram somadas a esse contexto, e "definem um panorama de tensões no que se refere à posse e propriedade das terras coloniais desde o início da sua demarcação até meados do século XX" (TRAMONTINI, 1994, p. 55).

Segundo Janaína Amado (2002, p. 44), vinte e um anos após a chegada dos primeiros imigrantes, isto é, em 1845, São Leopoldo ainda podia ser definia como região agrícola, sendo que $87,6 \%$ da sua população moravam na área rural. Dos 18.690 indivíduos contabilizados em 1858, mais de $77 \%$ vivia no entorno do Termo da Vila, isto é, nos distritos que eram as áreas mais rurais, destinadas aos imigrantes que chegavam anualmente e ao estabelecimento de unidades produtivas, cujo objetivo era desenvolver a pequena propriedade agrícola frente à expansão fundiária. Desde o início da imigração e colonização alemã no Rio Grande do Sul, os imigrantes e seus descendentes tomaram posse de sua propriedade/lote, plantaram e produziram excedentes. Assim, gradativamente, a colônia alemã de São Leopoldo se tornou um excelente espaço para abertura e fixação de uma venda ou um pequeno estabelecimento comercial (WITT, 2008, p. 176).

Esse modelo de estabelecimento comercial ocupava um lugar de destaque no cenário colonial, pois "constituíram-se numa das peças-chave para o desenvolvimento da Colônia Alemã", além disso, a venda também foi "um locus colonial privilegiado, onde o vendeiro e o freguês negociavam, repartiam novidades e tomavam partido nas mais diversas situações" políticas, religiosas e sociais (WITT, 2008, p. 14-15). O vendeiro ou negociante, além de controlar a vida das pessoas da comunidade local, manter contato com a capital da província, com certeza, era a única pessoa que sabia de tudo o que ocorria na região, naquilo que tange à política, à economia e à religião.

Nas vendas ou casas de negócio, havia uma variedade de produtos e se comercializava de tudo, como, por exemplo, gêneros agrícolas como milho e feijão, além de produtos agromanufaturados como banha, farinha, aguardente. Havia um grande sortimento de produtos originários do interior da colônia, mas também não podiam faltar os produtos adquiridos na capital da província. Janaína Amado (2002), destaca que a loja comercial surgiu logo 
depois que os imigrantes venceram as primeiras dificuldades. Ao mesmo tempo em que a região colonial se desenvolvia e expandia, surgiram casas e/ou firmas comerciais de importação e exportação de médio e de grande porte, nos principais centros urbanos, como por exemplo, em Porto Alegre, Rio Grande, Pelotas. Esses locais se tornaram espaços especializados nos mais diversos ramos comerciais. De acordo com Arthur Blásio Rambo (2017, p. 102), a partir da década de 1850 consolida-se uma

complexa rede de comércio, cobrindo toda a região colonial, compreendendo as bacias fluviais que formam o Guaíba, tendo como ponto de convergência Porto Alegre, capital do Estado. Simplificando o esquema, essa rede apresentava as seguintes características. Nas picadas do interior colonial estabeleceram-se casas de comercio locais, as "vendas". Elas compravam dos colonos os excedentes produzidos por eles: banha, feijão, batata, farinha de mandioca, galinhas, ovos... Essas mercadorias eram transportadas e entregues a estabelecimentos intermediários de maior porte, localizados junto aos terminais de navegação fluvial de São Leopoldo no Rio dos Sinos, em Caí e Montenegro no rio Caí, em Estrela, Lajeado e Mariante no Taquari no Rio Taquari, em Rio Pardo no Rio Pardo, em Cachoeira do Sul no Rio Jacuí. O mesmo fenômeno verificou-se nas estações que foram sendo implantadas ao longo da ferrovia, com seus ramais que cruzavam a região colonial. As mercadorias eram embarcadas no trem ou em barcos que os entregavam nas grandes casas de comercio sediadas em Porto Alegre. Toda essa movimentação davase também no sentido contrário. No retorno aos portos fluviais ou às estações do trem no interior, barcos e trens transportavam as mercadorias para cobrir as necessidades do interior colonial. Descarregados e armazenados em depósitos e armazéns, eram transportadas em carroções, puxados por várias parelhas de mulas, até as vendas nas picadas mais remotas.

É nesse contexto que surge um personagem que tinha a função de ser o intermediador entre o atacadista e o varejista; encarregado de percorrer a região colonial do Rio Grande do Sul, levar as novidades oferecidas nas casas comerciais importadoras, exportadoras, manufaturadas e industriais dos principais centros urbanos e depois retornar com as encomendas feitas pelos comerciantes. Diferentemente do mascate que levava e vendia as mercadorias ao longo do seu trajeto, o caixeiro viajante passou a ser mediador de vendas entre o colono local e o comerciante. Montado em sua mula, levava em bolsas e malas de couro "um talão de pedidos e catálogos (parecidos com uma lista de preços atual)" com a descrição dos produtos, além de amostras de mercadorias que não eram produzidas pelos colonos, em grandes baús (XAVIER et al, 2012, p. 44).

Quanto aos locais percorridos, é preciso lembrar que os caixeiros viajantes deslocavam-se por vastas regiões e, muitas vezes, inóspitas. Hilda Flores (p. 178) destaca que muitos caixeiros viajantes residiam em Porto Alegre e as viagens ao interior do Estado podiam durar semanas ou até meses. Desse modo, as casas comerciais ou "vendas" situadas ao longo da estrada se tornavam um local de parada obrigatória para conversar, descansar, negociar e namorar. Entre anos de 1880 e 1910, “o cenário de trabalho dos caixeiros viajantes cobria, não só toda a área de colonização alemã, de Taquara a Santa Maria e os primeiros núcleos de Passo Fundo, Soledade, Cruz Alta, ljuí, Santa Rosa”, mas incluía, sobretudo, "as colônias italianas mais antigas, principalmente o eixo Garibaldi - Bento Gonçalves Veranópolis, assim como praticamente toda a Campanha. Nos relatos de caixeiros constam viagens para fazer a praça até em Uruguaiana" (RAMBO, 2017, p. 103).

À medida que o caixeiro viajante ampliava seu raio de atuação e aumentava clientela, adquiria mais muares, formando tropa de até 20-30 animais. Quando o interior foi servido de malha viária, mesmo precária, o caixeiro atrelou a(s) mula(s) a uma carreta. Nas viagens fazia-se acompanhar por um ou mais Knecht, peão, que tangia os animais, auxiliava no carregamento e descarregamento de mercadorias e mostruários e no trato das mulas. O peão podia ser contratado em Porto Alegre, onde o caixeiro começava viagem, ou no interior (FLORES, 2000, p. 179-180).

A atividade comercial desenvolvida pelo caixeiro foi fundamental para o desenvolvimento do interior do Brasil. O deslocamento característico dessa atividade contribuiu para a configuração de seu trabalho e, principalmente, das relações familiares e afetivas desses trabalhadores (XAVIER et al, 2012, p. 
46). Ao longo de suas jornadas "conquistam muitos amigos e muito apoio na colônia, são convidados para padrinhos e a maioria encontra suas mulheres nas melhores famílias da colônia" (RAMBO, 2017, p. 104).No lombo de mulas e portando bolsas de couro, além de apresentar as novidades aos colonos; transportar amostras e distribuir as mercadorias em diferentes regiões; de arrecadar os pagamentos, expedir faturas e levar o dinheiro vivo para os patrões, numa época em que não havia uma rede bancária consolidada; os caixeiros viajantes também eram transportadores e recebedores de notícias, jornais e correspondências, vindas da capital do Estado, do país e do mundo.

Andrius Estevam Noronha (2012, p. 61), ao estudar os empresários de Santa Cruz do Sul, entre os anos 1905 a 1966, constatou que os comerciantes possuíam um papel significativo na compra e venda de mercadorias, fato este que contribuiu para que formassem o principal grupo de poder político local. Destaca ainda "que esse poder não surgia por acaso, pois o caixeiro-viajante desempenhava o papel de banqueiro e monopolizava a informação referente ao preço do tabaco e aos meios de escoamento da produção". Acerca da importância do caixeiro viajante, Olgário Vogt (1997, p. 94) reitera que ele era "o elemento de prestígio e poder político, era quem orientava os agricultores sobre o que e como plantar, sendo responsável pela introdução de novas técnicas produtivas na sua área de influência". Cabe destacar que os caixeiros também tinham a função de manter os colonos do interior informados sobre as novidades na política, quando não ingressavam na política, ocupando cargos na administração local.

A partir deste panorama e tomando os casos de João Emílio Bender, Pedro Adams Filho e A.J. Renner, evidencia-se um ambiente profícuo para que os caixeiros viajantes formassem uma rede social, estabelecendo vínculos benéficos para a ampliação de seu escopo econômico e pessoal, que se enquadram no que podemos definir como capital social. Para Nan Lin (2006), capital social consiste de recursos embutidos nas redes ou nas associações a que os indivíduos têm pertencimento. Ou seja, os caixeiros viajantes souberam utilizar dos recursos possíveis para atingirem um papel de maior atuação dentro de uma rede de influências, nas quais exercia um papel articulador.

Cabe aqui estabelecer algumas considerações acerca do conceito de redes sociais. Segundo Renato Pinto Venâncio,

trata-se de uma noção que se contrapõe à de "grupo social: em um grupo organizado, os indivíduos componentes formam um todo social mais abrangente, tendo objetivos comuns, papéis interdependentes e uma subcultura peculiar. Na formação de rede, por outro lado, somente alguns, e não todos os indivíduos componentes, têm relações uns com os outros" (VENÂNCIO, 2009, p. 240).

Neste sentido, Zacaria Moutokias (2000) explica que, dentro das redes sociais, alguns indivíduos possuem uma atuação que lhes confere uma ação de conexão, servindo como mediadores. Esses mediadores possuem vinculações dentro da rede, mas não ficam restritas ao âmbito familiar. Outros elementos podem ser agregadores, contribuírem para a formação e efetivação destas redes e seus objetivos. O historiador espanhol José Maria Imízcoz indica que o conceito de redes é adequado e contributivo quando utilizado nas tentativas de se analisar e compreender "los grupos de poder, facciones políticas, oligarquias locales [...], grupos mercantiles e financiemos" (IMIZCOZ, 2009). Vemos que as concepções de Zacaria Moutokias e José Maria Imízcoz se complementam, indicando que analisar os indivíduos e os grupos sociais dos quais participam ou aos quais se vinculam por essa óptica permite ver um panorama social mais amplo e complexificado. Além de concordarmos e nos apropriarmos desta concepção, também acordamos com a percepção de Michel Bertrand ao apontar que

se puede definir entonces a la red social como um complejo sistema relacional que permite la circulación de bienes y servicios, tanto materiales como inmateriales, entro de um conjunto de ralcaiones estabelecidas entre sus miembros, que los afecta a todos, directa 0 indirectamente y mui desigualmente (BERTRAND, 2000). 
Por sua vez, seja por meio de estratégias ou do fortalecimento de relações dentro das redes sociais, um componente importante destas relações é o capital simbólico (ou social) que os indivíduos possuem. Estas redes podem ser geradas em decorrência das relações estabelecidas ou ser, ao mesmo tempo, um fator de estabelecimento relacional, de articulação estratégica e de obtenção de objetivos diversos. Conforme conceitua Pierre Bourdieu, "o capital simbólico não é outra coisa senão - capital, qualquer que seja sua espécie, quando percebido por um agente dotado de categorias de percepção resultantes da incorporação da estrutura da sua distribuição" (BOURDIEU, 1989, p. 145). Ou seja, os indivíduos ou grupos dispõem de mecanismos cujo prestígio, carisma e influência de um ou mais membros favorecem certas posições ou espaços dentro do jogo social.

Ser caixeiro viajante ao longo da segunda metade do século XIX e início do século XX possuía algumas vantagens. Além de não ser necessário o investimento de um capital financeiro próprio, ele aprendia diariamente com outros caixeiros viajantes e comerciantes o conhecimento necessário sobre a sua profissão e acerca de distintas atividades comerciais. O elo de confiança estabelecido pelo proprietário e 0 seu caixeiro viajante também explica o fato de que várias casas de comércio alemãs de Porto Alegre tiveram como proprietários, antigos caixeiros viajantes. "Em alguns casos foram admitidos depois de pouco tempo como sócios das casas para as quais tinham viajado. Em outros casos as casas foram novamente postas a funcionar pelos antigos viajantes" (RAMBO, 2017, p. 111).

Por fim, salientamos que as atividades desenvolvidas pelos caixeiros viajantes foram extremamente importantes e intensas ao longo da segunda metade do século XIX e início do século XX. Em desuso, atualmente essa atividade econômica foi substituída pelo representante comercial, promotor de venda e outros profissionais, amparados por recursos tecnológicos.

\section{Referências}

AMADO, Janaína. A revolta dos Mucker. $2^{\underline{a}}$ ed. São Leopoldo: Editora UNISINOS, 2002.

BERTRAND, Michel. Los modos relacionales de las elites hispano americanas coloniales: enfoques y posturas. In: Anuario del IEHS, n. 15, Tandil, 2000.

BOURDIEU, Pierre. O Poder Simbólico. Lisboa: Difel, 1989.

SCHEMES, Claudia. Pedro Adams Filho: empreendedorismo, indústria calçadista e emancipação de Novo Hamburgo (1901-1935). Porto Alegre, 2006. Tese [Doutorado]. Pontifícia Universidade Católica do Rio Grande do Sul - PUCRS, Programa de Pós-Graduação em História, 2006.

FLORES, Hilda Agnes Hübner. Caixeiros viajantes: veículo de expansão econômica e cultural. 2000.

GRÜTZMANN, Imgart. Caixeiros-viajantes: tecedores de redes sociais, culturais e comerciais. In: GRÜTZMANN, Imgart; DREHER, Martin N.; FELDENS, Jorge A. Imigração alemã no Rio Grande do Sul: recortes. São Leopoldo: OIKOS, UNISINOS, 2008, p. 54-55.

ÍMIZCOZ, Jose Maria. Las redes sociales de las élites. Conceptos, fuentes y aplicaciones. In: MESA, Enrique Sosia; CARO, Juan Jesús Bravo; BARRADO, José Miguel Delgado. Las Élites en la Época Moderna: La Monarquía Española. Vol. I. Nuevas perspectivas. Córdoba: Universidad de Córdoba, 2009.

LIN, Nan. Social capital: a theory of social structure and action. 2. ed. Cambridge: Cambridge University Press, 2006.

MARTINHO, Lenira Menezes; GORENSTEIN, Riva. Negociantes e caixeiros na sociedade da independência. Rio de Janeiro: Secretaria Municipal de Cultura, Turismo e Esportes, Departamento geral de documentação e informação cultural, divisão de editoração, 1993.

MOUTOUKIAS, Zacarías. Familia Patriarcal o redes sociales: balance de una imagen de la estratificación social. Anuario del IEHS, Tandil, v. 15, 2000. 
NORONHA, Andrius Estevam. Beneméritos empresários: história social de uma elite de origem imigrante do sul do Brasil (Santa Cruz do Sul, 1905-1966). 2012. Tese (Doutorado em História) - Faculdade de Filosofia e Ciências Humanas, Pontifícia Universidade Católica do Rio Grande do Sul - PUCRS. Porto Alegre, 2012.

RAMBO, Arthur Blásio. O caixeiro viajante. In: Flagrantes: dos 190 anos da Imigração Alemã no Brasil. p. 101-124, (no prelo).

Perspectiva Econômica (Série Cooperativismo). São Leopoldo/RS, v. 37, n. 119, p. 95-111, 2002.

O caixeiro viajante. Perspectiva Econômica (Série Cooperativismo). São Leopoldo/RS, v. 37, n. 117, p. 121-139, 2002.

TRAMONTINI, Marcos Justo. A organização social dos imigrantes: a colônia de São Leopoldo na fase pioneira (1824-1850). São Leopoldo: Editora UNISINOS, 2003.

A questão da terra na fase pioneira da colonização. In: MAUCH, Cláudia. Os alemães no sul do Brasil. Canoas: Ed. da ULBRA, 1994, p. 55-64.

TRAMONTINI, Marcos Justo; ENGSTER, Maria Isabel Cristina. A imigração alemã na historiografia rio-grandense: Pellanda, Porto e Truda. In: DREHER, Martin N. (org.). Imigração \& Imprensa. Porto Alegre: EST; São Leopoldo: IHSL, 2004, p. 357-361.

VENÂNCIO, Renato Pinto. Redes de compadrio em Vila Rica: um estudo de caso. In: OLIVEIRA, Mônica Ribeiro de; ALMEIDA, Carla Maria Carvalho de (Org.). Exercícios de microhistória. Rio de Janeiro: FGV, 2009.

VOGT, Olgário. A produção de fumo em Santa Cruz do Sul - RS (1849-1993). Santa Cruz do Sul: EDUNISC, 1997.

XAVIER, Wescley Silva; BARROS, Amon Narciso de; CRUZ, Rafaela Costa; CARRIERI, Alexandre de Pádua. $O$ imaginário dos mascates e caixeiros-viajantes de Minas Gerais na formação do lugar, do não lugar e do entrelugar. Revista Administração, São Paulo, v.47, n.1, p.38-50, jan./fev./mar. 2012.
VIVÓ, Cristina Mazzeo de. Os vínculos interfamiliares, sociais e políticos da elite mercantil de Lima no final do período colonial e início da República: estudos de caso, metodologia e fontes. IN: OLIVEIRA, Mônica Ribeiro de; ALMEIDA, Carla Maria Carvalho de (Orgs.). Exercício de micro-história. Rio de Janeiro: FGV, 2009.

WITT, Marcos Antônio. Em busca de um lugar ao sol: estratégias políticas, imigração alemã. Rio Grande do Sul, século XIX. São Leopoldo: Oikos, Editora UNISINOS, 2008.

ZÚÑINGA, Jean-Paul. Clan, parentela, família, individuo: métodos y níveis de análisis. Anuario

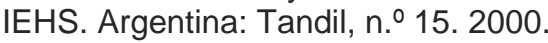

